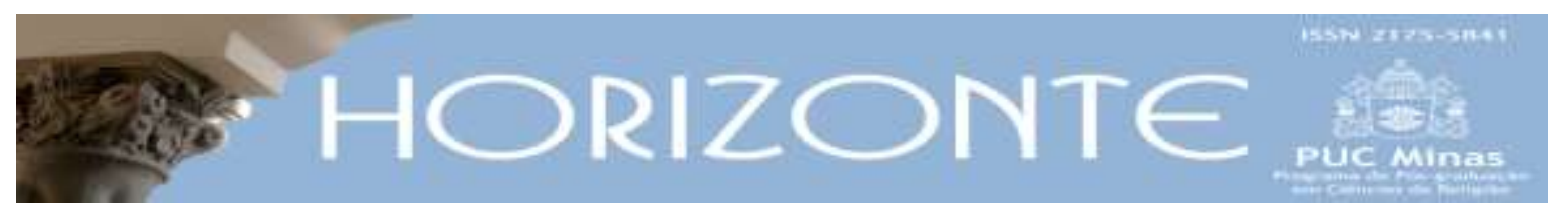

Temática Livre - Artigo Original



DOI - 10.5752/P.2175-5841.2016v14n44p1538

\title{
Corpos ditos pelo outro: \\ Uma leitura de Michel de Certeau ${ }^{1}$
}

Bodies spoken by the other: A reading of Michel de Certeau

\begin{abstract}
Geraldo Luiz De Mori*
Virgínia Buarque**

\section{Resumo}

O objetivo deste artigo é tematizar a reflexão de Michel de Certeau sobre os sentidos atribuídos ao corpo pela cultura ocidental, apontando também suas ressignificações pela religiosidade cristã. Para tanto, em termos metodológicos, atentou-se aos diálogos interdisciplinares promovidos por este autor, que transitava entre os campos da psicanálise, da história, da linguística, da filosofia, da teologia e da espiritualidade. Como primeira hipótese, postula-se que, para De Certeau, o corpo configura-se como uma "ficção" viabilizadora de práticas sociais, ou seja, uma instância de "autoridade" capaz de suscitar adesões, conflitos e transformações. Isto porque, segundo este intelectual jesuíta, o corpo constitui-se, simultaneamente, tanto como um aporte simbólico de poderes institucionalizados, como mediação para bricolagens, desvios e transgressões político-culturais promovidas no cotidiano. De forma concomitante, considerase como segunda hipótese que, como indicado por De Certeau, o corpo na tradição cristã foi também vivenciado como instância "mística", isto é, enunciador, por suas manifestações, do anseio por ser habitado por um outro/Outro. Sugerese ainda que a atualização dessa condição existencial e política no tempo presente viabiliza aos sujeitos positivarem sua intrínseca incompletude e fragilidade humanas, favorecendo, em decorrência, experiências histórico-sociais mais sensíveis e compartilhadas.
\end{abstract}

Palavras-chave: Michel de Certeau; Corpo; Ficção; Autoridade; Mística

\begin{abstract}
This article aims to schematize a reflection of Michel de Certeau regarding the various meanings attributed to the body by Ocidental culture, pointing out the resignifications of these meanings by the Christian religion. For this, in methodological terms, attention was given to interdisciplinary dialogue furthered by this author who easily moved among the fields of psychoanalysis, history, linguistics, philosophy, theology, and spirituality. As a first hypothesis, it postulated that for De Certeau the body is configured as a viable fiction of social practices, that is, an instance of authority capable of provoking agreements, conflicts and transformations. This is because, according to the aforementioned Jesuit, the body is constituted simultaneously both as a symbolic contribution to institutional powers as well as a mediation for political and cultural bricolage, departures and transgressions advanced in daily life. Concomitantly, it is considered, as a second hypothesis that, as indicated by De Certeau, the body in the Christian tradition was lived as a mystic instance, that is, as enunciating, by its manifestations, the desire to be habited by the other/Other. It is then suggested that an actualization of this existential and political condition now enables subjects to turn positive their intrinsic incompleteness and fragile humanness, favoring, as a result, historical and social experiences shared and felt.
\end{abstract}

Keywords: Michel de Certeau; Body; Fiction; Authority; Mysticism.

Artigo submetido em 29 de setembro de 2016 e aprovado em 21 de dezembro de 2016.

${ }^{1}$ Trabalho apresentado no Grupo de Pesquisa "Interfaces da Antropologia na Teologia Contemporânea", do PPG de Teologia da FAJE. Contou com a qualificada leitura crítica da mestra em Teologia Rosana Araújo Viveiros e dos demais membros do grupo.

* Doutor em Teologia (Centre Sèvres - Facultés Jésuites de Paris, França 2002). Diretor e Coordenador da Pós-Graduação de Teologia da FAJE, líder do Grupo de Pesquisa - GP Interfaces da Cristologia e da antropologia na teologia contemporânea. País de origem: Brasil. E-mail: geraldodemori@faculdadejesuita.edu.br

** Doutora em História (UFRJ), pós-doutora em Ciências Religiosas (Université Laval). Professora da UFOP. Integrante do GP As Interfaces da Antropologia na Teologia Contemporânea, da FAJE. País de origem: Brasil. E-mail: virginiacastrobuarque@gmail.com

Horizonte, Belo Horizonte, v. 14, n. 44, p. 1538-1564, out./dez. 2016 - ISSN 2175-5841 


\section{Introdução}

O cristianismo tem sido criticado, principalmente nos tempos mais recentes, por geralmente tratar de forma pejorativa a corporeidade e a sexualidade. Tal questionamento mostra-se procedente, caso se considere a maioria dos escritos teológicos e eclesiásticos produzidos em aproximadamente dois mil anos de história (RANKE-HEINEMANN, 1996). Não obstante, enfatizar a ótica da suspeição não foi a perspectiva privilegiada por vários autores que se dedicaram a estudar os sentidos do corpo no cristianismo (BROWN, 1990; GESCHÉ; SCOLAS, 2009), dentre os quais emerge a figura emblemática de Michel de Certeau, jesuíta de formação interdisciplinar que, em 9 de janeiro de 1986, morria acometido por um câncer no pâncreas. ${ }^{2}$ Este artigo, ao tematizar os sentidos do corpo para o jesuíta francês, pretende, portanto também ser uma homenagem póstuma a este intelectual, no marco simbólico de três décadas de seu falecimento:

Há 30 anos da morte de Michel de Certeau (1925-1986), [...] ainda são muitos e inumeráveis os traços distintivos e atuais, mas também as interrogações em aberto em torno dessa complexa figura do século XX [...]. Palavras como 'alteridade', 'errância', também 'disciplinar', e 'ruptura' às vezes 'refundadora' parecem ser, há tantos anos do seu falecimento, as outras chaves hermenêuticas mais adequadas para compreender a grandeza desse intelectual, natural de Chambéry, à luz da sua leitura da revolução estudantil de 1968 em Paris, da sociedade contemporânea (pense-se nos seus ensaios como $A$ tomada $d a$ palavra ou $A$ Invenção do Cotidiano), da sua interpretação do cristianismo pós-conciliar (basta reler os seus textos mais proféticos como Fragilidade do crer). [...] hoje há uma total redescoberta desse autor graças à sua 'errância' nos saberes e na sua arte de ter criado uma gramática capaz de compreender, em certo sentido, a situação social e religiosa do cristianismo minoritário na Europa (RIZZI, 2016).

\footnotetext{
${ }^{2}$ De Certeau publicou relevantes trabalhos de historiografia religiosa, entre livros e artigos. Na década de 1960, ele dedicou-se à espiritualidade inaciana: sua tese de doutorado em Ciências da Religião na Universidade de Paris V resultou numa densa introdução ao Le Mémorial de Pierre Favre, companheiro de Inácio de Loyola; em 1966, lançou o Guide Spirituel de Jean-Joseph Surin, bem como importante capítulo introdutório de Correspondance; em 1970, La Possession de Loudun. A partir, porém, de 1968 (expressivo marco cronológico da cultura contemporânea), ele lançou alguns livros considerados polêmicos, inclusive por muitos jesuítas: La Prise de Parole et Autres Écrits Politiques; L'Étranger ou I'Union dans la Différence, em 1969; L'Absent de l'Histoire, de 1973; Le Christianisme Éclaté, escrito em colaboração com Jean-Marie Domenach, em 1974; Politica e Mística. Questioni di Storia Religiosa, em 1975. Após um período em Genebra e na Califórnia, De Certeau editou em 1982, no campo da historiografia religiosa, seu derradeiro livro, La Fable Mystique. Outros textos do autor, também portando sobre mística, foram reunidos por Luce Giard, como La Faiblesse de Croire, em 1987; La Fable mystique, v. 2, em 2013.
} 
Michel de Certeau, ao refletir sobre os sentidos e os usos do corpo no âmbito do imaginário cristão, considera que a postura, inúmeras vezes assumida como "rejeição do corpo ou do mundo, luta ascética, ruptura profética, consiste apenas na elucidação necessária e preliminar de um estado efetivo, a partir do qual se inicia a tarefa de ofertar um corpo ao espírito, de 'encarnar' o discurso e dar lugar a uma verdade" (DE CERTEAU, 1982a, p. 108. Tradução dos autores). Ou seja, para o pensador jesuíta, o corpo cristão não se reduz à contingência existencial associada à tentação e ao mal, mas apresenta-se, principalmente, como instância de defrontação do humano com a falta, com a incompletude diante da Alteridade/das alteridades. Retoma-se aqui a questão proposta por Eduardo Gusmão de Quadros:

Seria possível encontrar um problema básico perpassando suas reflexões [de Michel de Certeau]? Assumindo o risco da simplificação, propomos que suas pesquisas giravam sempre em torno da alteridade. $O$ outro que nos escapa, como Deus, impossível de ser compreendido plenamente, é o princípio básico dos escritos certeaunianos (QUADROS, 2004, p. 104).

É sob esta ótica que Daniel Vidal, pesquisador da École des Hautes Études en Sciences Sociales, afirma que, para este autor, "o Absoluto vivencia-se na perda do corpo. A questão do sentido erodido [...] [em uma trajetória biográfico-cultural] entrelaça-se, portanto, à questão do corpo e de sua produção" (VIDAL, 1984, p. 190. Tradução dos autores).

Isso porque, aprofunda Michel de Certeau, o regime cristão é afetado por um postulado crucial: o da perda de um corpo, do corpo de Jesus, reproduzido pela perda do corpo de Israel. Dessa maneira, a palavra cristã só toma forma católica (universal) e pentecostal (espiritual) ao se separar de uma origem étnica e de uma hereditariedade: "Na tradição cristã, uma privação inicial do corpo não cessa de suscitar instituições e discursos que consistem em efeitos e substituições dessa ausência - corpos eclesiásticos, corpos doutrinais etc. [...]” (DE CERTEAU, 1982a, 
p. 110. Tradução dos autores). 3 Em suma, na ausência desse corpo inicial, o cristianismo "inventa" corpos - escriturístico, eclesial, místico (DE CERTEAU, 1982a, p. 110-111):

Como Foucault, provavelmente por razões comuns (de geração, de pertencimento a uma tradição, de exigência filosófica, de investigação histórica), mas sob formas distintas, o pensamento de De Certeau foi habitado por uma mesma questão filosófica: o corpo é pensável? Questão, em nossa história, alternadamente platônica, cristã ou freudiana, à qual Hegel havia acreditado evadir-se graças à historicidade. Por esta questão e para ela, De Certeau voltava-se ao que tinha embasado sua vida, isto é, ao que ele teria voluntariamente apostado o risco de viver, ou mais, segundo suas próprias palavras, 'sem o que viver não seria mais viver'; uma experiência crente, fundamentada sobre a história de um Deus feito homem, um corpo morto, um túmulo vazio, seguido pelo nascimento substitutivo de um corpo eclesial (GIARD, 1991, p. 43. Tradução dos autores).

Em paralelo às interpretações sobre o corpo no bojo da religiosidade cristã, De Certeau também reflete sobre sua concepção pela moderna cultura ocidental. Aí também, diz ele, o corpo não é considerado uma composição simplesmente biológica, pois se encontra dotado de dimensão simbólica com contornos eminentemente plurais, na qual a carência de um referencial afiançador de sentido também se faz sentir. Dessa maneira, em um colóquio dedicado à temática do corpo, Michel de Certeau afirma:

[...] nós procurávamos o corpo em todos os lugares e não o encontrávamos em lugar algum. A análise revela apenas fragmentos e restos. Ela reconhece cabeças, braços, pés etc., que se articulam em maneiras de comer, de saudar ou de se cuidar. São elementos colocados em séries particulares, mas o corpo, jamais o encontramos. Ele é mítico, tendo em vista que o mito é um discurso não experimental que autoriza e regulamenta práticas. $O$ que faz um corpo é uma simbolização sociohistórica característica de cada grupo (DE CERTEAU, 2002. p. 407).

Este artigo quer aprofundar tal reflexão de Michel de Certeau sobre os sentidos atribuídos ao corpo pela moderna cultura ocidental, apontando também

\footnotetext{
${ }^{3}$ Ver também GEFFRÉ, 1991, p. 178. Tradução dos autores: “O evento fundador do cristianismo, Jesus Cristo, 'permitiu' uma 'Escritura plural e comunitária'. Não haveria Igreja, nem escritura, nem tradição, sem a morte do Fundador que é um evento irremediavelmente passado. Nenhuma das 'objetivações históricas' é identificável à sua Origem ausente, mas nenhuma seria possível sem esse 'Outro' permanentemente em falta. É a kénosis que 'permite' a ressurreição, no sentido mais amplo do termo”.
} 
suas específicas ressignificações pela religiosidade cristã. Para tanto, parte-se da premissa, também formulada por De Certeau, de que esses dois imaginários sociais, 4 a despeito de suas diferenças na abordagem do sagrado, compartilham enfoque similar acerca do corpo: tanto para o cristianismo como para a modernidade, o corpo configura-se como uma "ficção" viabilizadora de práticas sociais. Por sua vez, tal concepção implica em que o corpo também consista, no âmbito desses imaginários, em uma instância de "autoridade" capaz de suscitar adesões, conflitos e transformações. Operante como "ficção" e "autoridade", o corpo então se constitui, para De Certeau, simultaneamente tanto como um aporte simbólico de poderes institucionalizados, como mediação para bricolagens, desvios e transgressões político-culturais promovidas pelos sujeitos em seu cotidiano.

Também postula-se que, segundo De Certeau, o corpo possa ser dotado de uma singular configuração epistêmico-existencial, ao manifestar-se como uma enunciação, em linguagem semiótico-simbólica, do desejo do sujeito pela relação com um outro/Outro, com quem venha a unir-se - trata-se, neste caso, de um corpo “místico" (DE CERTEAU, 1994, p. 297). De acordo com De Certeau, é justamente a ressonância dessa voz das alteridades/da Alteridade que permite ao corpo ser "informado" (receber a forma), antes mesmo que a inteligência possa conhecê-lo ou figurá-lo (DE CERTEAU, 1982a, p. 408).

Indica-se ainda que se este artigo, nos três tópicos a seguir desenvolvidos, dedicou-se a analisar os sentidos do corpo como "ficção", “autoridade" e "mística” para Michel de Certeau, ele veicula ainda uma esperança, retomada na conclusão: o pensar uma corporeidade que, assumindo a fragilidade da condição humana, tantas vezes "encarnada" nos corpos ao longo da história (por diversos processos de subordinação político-cultural), possa ser ressignificada no âmbito de relações mais sensíveis e compartilhadas, tanto por sujeitos que vivenciem a fé cristã quanto por aqueles que, em meio à modernidade, reconheçam em si um desejo fundante pelo encontro com outro.

${ }^{4}$ Para o conceito de imaginário social, ver: BACZKO, 1985. 


\section{Fiç̧ão, instituição, mística: categorias certeaunianas na abordagem do corpo}

Com base em seus estudos sobre o cristianismo e a modernidade, Michel de Certeau elabora uma primeira assertiva acerca do corpo: ele configura-se como uma "ficção" - produção de sentidos catalizadora de um "efeito do real", por metaforizar balizas de verdade norteadoras da vida social (DE CERTEAU, 2011):5

Deste corpo fugidio e disseminado, embora controlado, cada grupo tem necessidade de ter referências e imagens que tenham valor topográfico e canônico. São representações substitutivas - 'ficções' de corpos, se ao termo 'ficção' for dado o sentido de produção. Esses sucedâneos têm a dupla função de representar o corpo por meio de citações (fragmentos representativos) e de normalizá-lo com a ajuda de modelos. Eles têm um papel análogo àquele dos 'exemplos', que, em uma gramática, fornecem igualmente representações fragmentárias da língua e de modelos para seu bom uso (DE CERTEAU, 2002. p. 408).

Como marco ficcional, o corpo mostra-se altamente performativo, sustentando dinâmicas sociais que se desdobram em miríades de ações na vida cotidiana. Com isso, De Certeau conclui que a experiência interpessoal do corpo manifesta-se então como uma "autoridade", termo compreendido no circuito da hermenêutica certeauniana, cujos sentidos foram construídos justamente com base na reflexão histórico-teológica provinda do cristianismo. Para De Certeau, "autoridade" pode ser também entendida como uma "permissão" ou "potencialização" do outro, pela qual a existência é viabilizada em novas dimensões. É nessa perspectiva, ainda segundo ele, que a autoridade "permite" da mesma maneira que um poema ou um filme inaugura uma percepção que não era possível antes dele: depois de lê-lo ou assisti-lo, não se pensa mais da mesma forma. Em ótica similar, o que a autoridade suscita de novo, não é redutível a ela mesma, não é mera repetição de si.

\footnotetext{
${ }^{5}$ Segundo PINTO, 2012, p. 198: "sente-se falta de uma elaboração mais sólida, da parte de Certeau, sobre o que ele entenderia por ficção e por ciência. Há certa obscuridade e hesitação do autor na definição desses termos, complexos e 'perigosos', talvez porque em seu entender, para o domínio histórico, ciência e ficção não existam em suas formas 'puras', mas tão somente nessa estranha mistura”. Embora a autora reporte-se especificamente à abordagem do conhecimento histórico em tal trânsito entre ciência e ficção, é possível traçar analogias com os sentidos atribuídos ao corpo pelos saberes ocidentais, da religiosidade aos estudos médico-biológicos, abarcando-se também os campos da estética, da publicidade etc.
} 
Não obstante e de forma aparentemente paradoxal, como analisado por De Certeau em uma segunda assertiva, este corpo-autoridade mostra-se, simultaneamente, indissociável do aporte de instituições e poderes que legitimam (ou conflituam com) os discursos que buscam regularizar seus usos:

Eu gostaria de dedicar uma última parte à questão do corpo e, através dela, à questão da instituição, presença insistente e velada para Michel de Certeau [...] a instituição permanece, para ele, um 'objeto segundo', mas não secundário. Ela é, a seus olhos, este lugar de poder que rege o corpo eclesial [...]. Certeau não ignora a instituição, pelo contrário, ele não cessa de reencontrá-la em cada domínio que explora pelo pensamento, ao mesmo tempo que não cessa de subtrair-se a ela, com essa mobilidade das táticas do 'frágil', recusando a 'lei do lugar' (GIARD, 1991, p. 42-44. Tradução dos autores).

Logo, é importante destacar que, para De Certeau, “a instituição atribui uma localização, mas não uma autoridade” (DE CERTEAU, 2011, p. 93). Esta é promovida pelas ficções, pelos sentidos aos quais se confere credibilidade. Por isso, as expressões do corpo não se reduzem ao institucional, mas lançam contínuos apelos à recriação de si através de contatos com o outro.

Michel de Certeau discorre ainda sobre o processo de articulação desse corpo-"ficção"-“autoridade" à palavra, mediante um ato de nominação de si pelo outro. Isto porque "ser alguém" implica, tanto no cristianismo como na modernidade, ser reconhecido, ser amado, e em tais imaginários, uma expressão basilar desse afeto é ter seu nome proferido por aquele que se ama (DE CERTEAU, 1994, p. 257), em uma escuta que abarca tanto a subjetividade quanto o corpo.

Esse nome imposto pelo outro tem, igualmente e, sobretudo, a característica de não depender de nenhuma autorização. [...] O nome não é autorizado por qualquer sentido; pelo contrário, ele autoriza uma significação, à maneira do poema que não tem nenhum precedente e cria possibilidades indefinidas de sentido. [...]; em vez de ser crível, ele leva, sobretudo, a crer. [...] A crença é baseada na tonalidade de uma voz e ela leva a crer que se é reconhecido, conhecido, até mesmo amado [...] ela o institui [o sujeito] finalmente, em alguma parte, fixando-lhe um lugar [um corpo] que põe termo à sua deriva, além de conferir-lhe lugar definido pelo nome com o qual é chamado por ela. [...] Ele transforma-se no corpo do significante; ora, a palavra escutada designa precisamente esta transformação (DE CERTEAU, 2011, p. 194-195). 
Simultaneamente, Michel de Certeau também apresenta a peculiaridade do corpo na vivência mística. Para ele, a mística consiste em uma experiência subjetiva e corpórea de ser transpassado por uma Alteridade - o sujeito percebe-se perpassado ou habitado por um Outro, inclusive em sua intimidade corporal:

Michel de Certeau trouxe à baila que o místico inscreve em seu próprio corpo o desapossamento do 'eu', quer dizer, a perda de tudo que o faz, a princípio, o referencial do corpo, e sua glória, e que, subitamente, o reduz a rejeitos, resíduos, ou em todo caso predicados não essenciais do ser, aí incluídas todas as formas de discurso que são, elas também, desfeitas. Há o que deve ruir, o que deve ser perdido, ao qual se acordava um valor, um crédito, um sentido. A mística é um dispositivo radical de privação. Ela representa um movimento de despossessão voluntária do que constitui a mundanidade dos atributos imaginários do ser, quer dizer, certo número de propriedades, de qualidades, de insígnias utilizadas continuamente para atribuir uma representação ou figura a si. Isto o corpo místico o traduz e o coloca em cena à maneira do que atravessa o sujeito na experiência da psicanálise (CAUSSE, 2014. Tradução dos autores).

Nos tópicos seguintes serão apresentadas de forma mais detalhada cada uma das três categorias empregadas por De Certeau para interpretar os sentidos do corpo na modernidade ocidental, em suas interfaces com o imaginário cristão, tão hegemônico durante vários séculos.

\section{Corpos ficcionais}

Como se processa a significação do corpo, ou seja, seu processo de "ficcionalização"? Através do cotejamento de diversas publicações de Michel de Certeau, que abarcam a cultura ocidental sob um viés diacrônico (do medievo à contemporaneidade), é possível constatar que, segundo ele, até aproximadamente o século XII, o corpo era entendido como um signo capaz de expressar uma ordem ontológica, uma vez que Deus fizera o mundo conforme sua Vontade e o humano "à sua imagem e semelhança”, ainda que sob critérios de proporção e de participação, jamais de completa identidade. Dessa maneira, o corpo portava 
[...] o estatuto que têm os significantes de serem registros estáveis [...], de poder distinguir-se nomeando o pensável (uma ratio) que organiza os seres, inserindo-os em sistemas de maneira a soletrar a grande narrativa paradigmática do universo, a manifestar-se como um conjunto concebido pelo Logos, a ler e fazer ler como a revelação 'natural' que, através da textura complexa do mundo, um Locutor endereça a seus destinatários (DE CERTEAU, $1982^{\mathrm{a}}$, p. 84. Tradução dos autores).

Como signo, o corpo foi empregado para traduzir a presença do divino na ordem do mundo, mediante uma tripla e articulada manifestação - corpo eucarístico, corpo eclesial, corpo místico de Cristo. ${ }^{6}$ Até o século XII, o suporte de "autoridade" desta associação encontrava-se na instância velada, encoberta, da analogia. Esta fora a perspectiva defendida por Ambrósio de Milão, já no século IV, que privilegiava na abordagem da alegoria sacramental (corpo eucarístico), a dimensão de mysterium, de sinal que des/vela a atuação salvífica de Cristo na história. Contudo, a passagem para o chamado "Baixo Medievo" foi acompanhada por uma mudança importante no entendimento do corpo eucarístico. Assim, Hugo de São Vitor, além de reiterar sua dimensão analógica de signo sacramental, também enfatiza sua eficácia santificadora. São Tomás de Aquino, com base em Aristóteles, então entrecruza a leitura de Agostinho com Hugo de São Vitor, indicando que a função sacramental (corpo eucarístico) apresenta-se como basilarmente epifânica (ela vinculava-se ao visível) e performática (ela suscitava uma adesão, uma transformação/santificação e um agir) (ROSIER-CATACH, 1998). Do velado ao manifesto, do descritivo ao operatório: a partir de então, mostrava-se também necessário que o corpo eclesial (ou institucional da Igreja), sua dimensão visível, fosse sumamente fortalecido, o que ocorreu mediante a restauração política do Papado e a reforma administrativa do clero, paralela à expansão quantitativa das comunidades religiosas.

\footnotetext{
${ }^{6}$ Henri de Lubac, em 1944, na obra Corpus Mysticum: l'eucharistie et l'Église au Moyen Âge: étude hisotirque. Paris: CERF, 2009 (Oeuvres Complètes, v. 15), realiza um estudo magistral sobre a evolução ocorrida na alta Idade Média entre os termos corpo eucarístico, corpo eclesial e corpo místico de Cristo.
} 
A promoção de uma nova reforma eclesial entre os séculos XIV-XVI reforçou, por sua vez, o entendimento do corpo eucarístico e eclesial como signo cada vez mais transparente, embora sem descurar de sua faceta soteriológica:

[...] "o 'mistério', corpo sacramental, é apreendido sob a formalidade filosófica do signo, quer dizer, de uma 'coisa' visível que designa outra, invisível: a visibilidade desse objeto substitui a celebração comum, operação comunitária; ela indexa a proliferação de efeitos secretos (de graça, de salvação) que compõem a vida real da Igreja" (DE CERTEAU, 1982a, p. 113. Tradução dos autores).

Para tanto, a Igreja Romana considerou imprescindível articular a significação visível do sacramento e da Igreja (princípio da unidade) com o poder clerical (princípio hierárquico). Com base no Concílio de Trento, esta pastoral baseada num corpo capaz de sustentar a restauração de uma Igreja visível terá grande emprego: o mistério da instituição deve ser manifestado pela pluralização das pregações, que devem ser simples, claras, adaptadas a cada grupo social, de forma concomitante à ostentação visual dos marcos de fé (como as exposições do Santíssimo Sacramento) e à narrativa das vidas dos santos e de milagres (mas, neste último caso, uma realidade secreta sobressai sobre a transparência então atribuída ao signo) (DE CERTEAU, 1982a, p. 113-115). A proliferação de confrarias e congregações religiosas participa dessa procura intensiva por um corpo que torne visível e hierárquico um "espírito" (um anúncio).

Portanto, nesses primórdios da cultura moderna, já subsiste toda uma ênfase no visual: a revolução da pintura no século XV e a invenção da perspectiva; a enciclopedização do saber; o papel da ótica na cientificidade moderna. Modificação antropológica: a visão substitui lentamente o toque e a audição (DE CERTEAU, 1982a, p. 120). Constitui-se assim um espaço de visibilidade, numa "transparência" que tomará, no século XVII, a figura (epistemológica) da representação. A diferença, aqui, entre o corpo anteriormente entendido como alegoria e sua nova leitura como representação, é a de que a dimensão assertiva, explicitadora de sentidos, ganha relevo sobre significações veladas, e mesmo sobre as propositivas 
(acerca de mudanças que podem ser suscitadas). Já em termos políticos, na interface com o imaginário teológico ainda preponderante, a fórmula "Este é o meu corpo”, da consagração eucarística, irá desdobrar-se na figuração do corpo do rei, que em sua dupla faceta de contingente (já que os monarcas falecem) e atemporal (pois a Coroa perdura), endossa simbolicamente o processo de centralização monárquica, bem como o controle dos distintos corpos eclesiais e das multidões de súditos (DE CERTEAU, 1982a, p. 116-117; KANTOROWICZ, 1998):

[...] é impossível compreender a intensa politização da segunda metade do século XVII independentemente da interrogação que abre a questão do sujeito e da disseminação que atomiza os corpos. O poder do Estado aumenta à medida que há dispersão dos corpos. A prova, entre muitas outras, é o Leviatã de Hobbes: o Estado é o novo corpo do qual o rei é a cabeça. A sociedade civil segue a mesma evolução. As regras do decoro, da civilidade, das boas maneiras ou da disciplina pedagógica se multiplicam, então, como se fosse necessário, por meio delas, conter os corpos instáveis, contraditórios e agitados de paixões ou de 'impulsos desordenados'. Como se fosse necessário produzir socialmente, por meio desta regulamentação dos corpos, uma ordem que o cosmos não garante mais (DE CERTEAU, 2002, p. 411).

Nos séculos seguintes, com o aprofundamento da secularização, a representação emblemática do corpo é transposta da figura do rei para a dos organismos, inclusive do ser humano. Assim, o corpo individual tornou-se a unidade básica da sociedade, após um tempo de transição, em que aparecia como a miniatura da ordem política ou celeste - um microcosmo. Mas esse corpo é visto sob o prisma da física mecânica, como uma complexa maquinaria de bombas, tubos, filtros, num movimento de pulsões, pressões, modificações de equilíbrio. Peças que podem ser substituídas por elementos artificiais, a culminar na possibilidade de construção de corpos autômatos. Portanto, o corpo é passível de reparação e mesmo fabricação, em tempos cibernéticos. Em ambos os casos, como organismos ou máquinas, os corpos são considerados representações autonomizadas e legíveis (DE CERTEAU, 1994. p. 234): 
A medicina moderna é uma imagem decisiva deste processo, a partir do momento em que o corpo se toma um quadro legível e, portanto, traduzível naquilo que se pode escrever num espaço de linguagem. Graças ao desdobramento do corpo, diante do olhar, o que dele é visto e o que dele é sabido pode se superpor ou se intercambiar (se traduzir). O corpo é um código à espera de ser decifrado [...] cadáver mudo exposto ao olhar (DE CERTEAU, 1982b, p. 14).

Simultaneamente, tal entendimento estende-se à apreensão epistêmica da cidade e mesmo do "corpo social", ambos transformados em espaços "legíveis" (DE CERTEAU, 1994, p. 232). Note-se, porém, que Michel de Certeau, sobretudo em seu livro A Invenção do Cotidiano, realçou a cidade como um corpo ou espaço habitado, onde a "ordem", em sua representação cartográfica-arquitetural, era continuamente extrapolada:

Se retomarmos Michel de Certeau, poderíamos localizar esse conhecimento nos usos e apropriações constituídos no e pelo movimento [...] O corpo, ainda que comporte sempre inventividade e seja capaz de inscrever plasticidade mesmo em ambientes blindados, é marcado pelo espaço, pela reprodução social do espaço. $\mathrm{O}$ espaço, ainda que nunca esteja acabado, adquire diferentes sentidos de acordo com os modos de corporar que se lançam sobre ele. Assim, o que é feito dos espaços públicos da cidade impacta o corpo. [...] Em qualquer uma das densidades possíveis da conexão espacial (que sempre simbólica) público/privado, há sempre impactos aos modos de subjetivação. Por isso, a produção dos espaços privados, em sua conexão gradual aos espaços públicos, condiciona a experiência corpo-subjetivação (NOGUEIRA, 2012, p. 7).

Também, a partir de meados do século XVIII, este corpo coletivo passa a ser representado como expressão do inédito e do conflito - trata-se de uma "era de revoluções", da queda dos regimes monárquicos centralizados, pelos movimentos liberais e de inspiração socialista, bem como da transformação da produção, com a industrialização. Na tentativa de decodificação das "lógicas" implícitas a esses corpos sociais, surgem as ciências humanas:

Uma medicina e uma historiografia modernas nascem quase simultaneamente da clivagem entre um sujeito supostamente letrado, e um objeto supostamente escrito numa linguagem que não se conhece, mas que deve ser decodificada. Estas duas 'heterologias' (discursos sobre o outro) se construíram em função da separação entre o saber que contém o discurso e o corpo mudo que o sustenta (DE CERTEAU, 1982b, p. 14). 
Nesse sentido, a história científica seria uma variante tardia desse trabalho, que procura, desde então, produzir, com discursos, novos corpos sociais - a exemplo de nações, partidos, classes. No intuito de "dar um corpo" à perda de uma experiência vivenciada em um determinado tempo, o saber histórico é formulado a partir de exumações em arquivos e documentos: "Trabalho alquímico da história: ela transforma o físico em social; [...] ela produz imagens da sociedade com pedaços de corpos" (DE CERTEAU, 2002, p. 409). Desta maneira:

Como prática (e não como os discursos que são o seu resultado), ela simboliza uma sociedade capaz de gerir o espaço que ela se dá, de substituir a obscuridade do corpo vivido pelo enunciado de um 'querer saber' ou de um 'querer dominar' o corpo, de transformar a tradição recebida em texto produzido, finalmente de constituir-se página em branco que ela mesma possa escrever (DE CERTEAU, 1982b, p. 16).

Por fim, perfazendo um circuito, De Certeau reitera então como, por meio das instituições e agenciamentos socioculturais, os corpos são representados como metáfora desse sentido histórico:

"De De Certeau podemos tirar, ainda, a ideia do corpo como metáfora da história. O corpo em sua plasticidade repara-se, educa-se, fabrica-se para representar e dar legitimidade ao discurso da nação, do gênero, da classe. Nas palavras de De Certeau, o corpo é aquele 'que leva os vivos a se tornarem sinais da unidade de um sentido' (1994, p. 232), ou seja, de uma identidade" (FLORES; NORA, 2011, p. 5).

\section{Corpos institucionalizados e desviantes}

Por quais meandros a produção ficcional do corpo confere aportes (ou, pelo contrário, fragiliza a atuação) de instituições e poderes? Esta interrelação era considerada bastante complexa por Michel de Certeau, face à diversidade de elementos envolvidos, com seus distintos códigos e linguagens, estendendo-se desde o nascimento até o luto dos sujeitos. A análise de De Certeau, promovida de forma sincrônica, privilegiando um viés sociológico-político, afirma que através de operações simbólicas, instituições como a família, a escola, o trabalho etc., 
empenham-se por formatar os corpos em significantes de regras de ordenação social (eles são, assim, "contextualizados”). Tais simulacros corporais da ordem passam, com isso, a deter um valor tanto representativo como normativo: "Haveria um código mais rigoroso e mais ritualístico do que o da vestimenta? Ela classifica, separa, hierarquiza, ratifica os contratos secretos do grupo. Mantém as 'distinções' sociais, as condições culturais e as distâncias entre as classes. [...]” (DE CERTEAU, 1995, p. 48).

O mais intrigante no tocante às sociedades ocidentais contemporâneas, acrescenta De Certeau, é que tais padronizações são acompanhadas por grande fluidez das vivências interpessoais, de "caminhantes, pedestres, Wandersmänner, cujo(s) corpo(s) obedece(m) aos cheios e vazios de um 'texto' urbano que escrevem [através de suas práticas fragmentárias] sem poder lê-lo" (DE CERTEAU, 1994, p. 171). Assim, o corpo deixa de comportar-se como um lugar - dotado, portanto de fixidez, em formato patrimonial, herança a administrar, para ser empregado como um campo de transpasses, atravessamentos, choques, derivas... (GIARD, 1991). Dessa maneira, o corpo torna-se um campo de moventes subversões, comportando

[...] assim mil variações e improvisações [...] O conjunto, ao mesmo tempo codificado e móvel que forma este corpo, escapa à compreensão, tanto quanto a língua. Percebem-se performances particulares, que seriam os equivalentes a frases ou estereótipos: comportamentos, gestos, ritos. [...] Este corpo tão rigorosamente controlado é, por paradoxo, a zona opaca e a referência invisível da sociedade que o especifica. Ela se obstina em codificá-lo sem poder conhecê-lo (DE CERTEAU, 2002, p. 408).

Contudo, a pressão institucional para uma apropriação panóptica desses corpos é também bastante intensa: específicos instrumentos, de apelo mercadológico-publicitário ou de feitio terapêutico-cirúrgico, geralmente associados a um determinado modelo de bem-estar, buscam incessantemente reintegrar elementos desviantes à norma. Mas, continua De Certeau, a própria ideologia médica adotou uma importante combinatória: junto a uma anterior terapêutica da extração, em que o mal é um excesso, ela também incorporou uma 
terapêutica de acréscimos, em que o mal é uma falta (DE CERTEAU, 1994, p. 233234).

Quando tais medidas não se mostram funcionais, as instituições contemporâneas empenham-se então por eliminar tudo o que não se identifica com a lógica produtivista do mercado: detritos, delinquência, doença, velhice, moribundos... Todos esses desviantes, figurados e reconhecidos através de seus corpos, são retirados do circuito do pensável, mediante a privação do reconhecimento público. Tornam-se inomináveis, e paralelamente, tornados objetos da ação "asséptica” de setores técnico-especializados (hospitais, prisões, depósitos de lixo). Lá perduram como exilados, ou são "reciclados", a fim de serem reenviados à dinâmica do progresso. Em uma sociedade na qual não mais ser capaz de intervir é entrar na região de insignificância, o desaparecimento dos sujeitos é compensado e camuflado pela multiplicação das tarefas (DE CERTEAU, 1994, p. 294-295).

Já em situações de risco ou de crise, a lei opera ainda mais rigorosamente sobre os corpos, seja por privações, seja através de dor física punitiva (DE CERTEAU, 1994. p. 231-232). Esta autoridade impositiva, eliminadora da diferença, culmina então em práticas de tortura e morte:

A tortura procura produzir a aceitação de um discurso de Estado pela confissão de uma perversão: afinal, ao torturar sua vítima, o carrasco pretende reduzi-la a ser apenas isso, um lixo, a saber, o que o próprio carrasco, além de ser, sabe que é, mas sem confessá-lo. A vítima deve ser a voz dessa safadeza, denegada por toda parte, e que serve de suporte [...] à representação da 'onipotência' do regime, ou seja, de fato, à 'imagem gloriosa' de si mesmo que tal regime fornece a seus adeptos pelo fato de reconhecê-los [...] (DE CERTEAU, 2011, p. 197).

Todavia, mesmo em sistemas demasiadamente autoritários e que dispõem de uma grande rede de vigilância social, é difícil manter por muito tempo a capacidade de suscitar adesões. Não casualmente apela-se à violência, mas quanto maior a força explicitamente empregada, menor a autoridade. E a sofisticação da disciplina não é capaz de compensar o desengajamento das pessoas, solapando os 
sistemas a partir de dentro (DE CERTEAU, 1994, p. 281). Mais e mais as táticas corporais transgredem os códigos sociais inscritos sobre a pele:

O indivíduo certeauniano nos permite pensar, [por exemplo], o uso da tatuagem como uma forma de escapar à classificação dada pela cultura, no momento em que este indivíduo age para modificar o seu corpo, tornando-o diferente do padrão geral que rege o social, embora ele recaia numa nova forma de classificação (SOUSA, 2009).

Dessa maneira, o corpo pode constituir-se, segundo De Certeau, na fronteira derradeira - e, por isso, crucialmente fundante - das intersubjetividades. Através das inscrições nele contidas, é possível sustentar-se uma identidade almejada, uma resistência a uma espoliação, a abertura a uma esperança. Como exemplo, ele cita o rito judaico da circuncisão:

Com efeito, [a circuncisão] significa, na medida em que marca com uma perda e pelo ato de perder. Diferentemente da relíquia, que é guardada, ou dos estigmas, que são acrescentados, a circuncisão significa ser raptado. Ela, aliás, não é mais um nome, mas o gesto que faz no corpo individual aquilo que diz do corpo social. Costume (Sitte) primitivo, existente fora do acontecimento que o torna significante, criado como um fato bem antes de se tornar um documento, adquire, pelo fato de ser deportado e privado do seu contexto, a mudança de estatuto que de signo da pertença egípcia o transforma em lei de pertença judia. [...] A circuncisão é, pois, inscrição, escultura ou gravura da lei sobre o corpo quer dizer, o que faz sentido suprimindo (diferentemente da pintura, que acrescenta) -, prática privadora e, por este motivo, produtora de sentido (DE CERTEAU, 1982b, p. 330-331. Grifos da publicação original).

Este processo de demarcação identitária através dos corpos é promovido, de forma concomitante, mediante projeções sobre o estrangeiro, que precisa ter sua diferença visibilizada:

O que a literatura de viagem está produzindo é o selvagem como corpo de prazer. Frente ao trabalho ocidental, as suas ações fabricadoras de tempo e de razão, existe, em Léry, um lugar de lazer e de prazer, festa do olho e festa do ouvido: o mundo tupi. A erotização do corpo do outro - da nudez e da voz selvagens - caminha junto com a formação de uma ética da produção. Ao mesmo tempo que um ganho, a viagem cria um paraíso perdido: relativo a um corpo-objeto, um corpo erótico. Esta imagem do 
outro, sem dúvida, representou na episteme ocidental moderna um papel ainda mais importante do que o representado pelas ideias críticas veiculadas na Europa através dos relatos de viagem (DE CERTEAU, 1982b, p. 225-226. Grifos da publicação original).

Observe-se, porém, como assinala De Certeau, que apesar do sofrimento de ter o corpo escrito pela lei, ou pelo olhar/dizer do outro, tal processo vem acompanhado por um prazer, o de ser reconhecido, o de tornar-se identificável e legível (DE CERTEAU, 1994, p. 232):

A lei feita carne pela escrita está registrada no corpo; ela coloca o corpo, chama o corpo, marca o corpo. Aqui, há um paradoxo: o corpo chamado passa por um sentimento de dor e prazer. Há o prazer de estar sendo chamado e, então, reconhecido: 'Dá-me teu corpo e eu te dou sentido, faço-te nome e palavra de meu discurso', diz a lei. Porém, tal inscrição implica em dor, uma vez que o corpo se opõe à lei. A fronteira final dessa oposição seria o grito. Para Certeau, talvez o grito seja a única expressão que não é colecionada pela instituição (JOSGRILBERG, 2005, p. 51-52).

\section{Corpos místicos}

É precisamente no bojo da aspiração de ser visto/dito pelo Outro, mas de forma não circunscrita à lei, que se delineiam de forma muito singular os corpos místicos. Foi sobre esses corpos que Michel de Certeau debruçou-se, num estudo de duas décadas, que mesclou cronologia e sincronia, história e linguagem. Como se configuram tais corpos místicos na religiosidade e na cultura ocidentais? Para o jesuíta francês, na experiência mística, o corpo mantém-se como um lugar vacante e, através dele, o sujeito vislumbra aquilo que ele não é, o que não tem, o que jamais poderá capitalizar. Abre-se então o espaço do desejo pelo ser nominado, tocado pela Alteridade, que assim "engendra um corpo vivente, pulsante, produtivo", capaz de mediar relações e transformações (CAUSSE, 2014. Tradução dos autores).

Gritos e lágrimas: afásica enunciação daquilo que sobrevém sem que se saiba de onde (de que obscura dívida ou escritura do corpo), sem que se saiba como [...]. Esses lapsos de vozes sem contexto, citações 'obscenas' de corpos, ruídos à espera de uma linguagem, parecem certificar, por uma 
'desordem' secretamente referida a uma ordem desconhecida, que existe o outro. Mas ao mesmo tempo vão contando interminavelmente (é um murmúrio que jamais para) a expectativa de uma impossível presença que muda em seu próprio corpo os vestígios que deixou (DE CERTEAU, 1994, p. 257-258).

O interesse de Michel de Certeau pela mística como uma concomitante experiência de esvaziamento e transpasse de si por uma alteridade/Alteridade, mediada pela corporeidade, conduziu o teólogo Dominique Bertrand a qualificar seus escritos como uma "teologia negativa", portadora de vínculos implícitos com a obra de Pseudo-Dionísio (ou Dionísio Areopagita), pseudônimo de um teólogo desconhecido, que viveu no final do século V (1991, p. 227-252). Note-se que no período em que Michel de Certeau iniciava suas pesquisas em história religiosa, na década de 1950, algumas obras da Patrística passaram por um decisivo processo de releitura, dentre elas as de Pseudo-Dionísio.7

Para Bertrand, existe grande afinidade entre De Certeau e este autor de vários tratados, entre os quais $A$ Teologia Mística e $A$ hierarquia eclesiástica. Isso porque, enquanto nas sociedades laicizadas, o termo "hierarquia" passou a significar um processo de distinção e sobreposição de valores (e poderes) em luta concorrencial, na obra dionisiana o vocábulo portava um sentido peculiar:

Segundo os atuais intérpretes de Dionísio, a hierarquia, para o Areopagita, implica num 'começo santo': 'em cada qual, segundo seu ser, a hierarquia é o começo (archie $=$ começo) santo (hier $=$ santo) que faz a unidade entre ele e a tearquia (o começo que é Deus mesmo); ela é em si mesmo o movimento interior de unificação, próprio a cada ser (BERTRAND, 1991, p. 113-114. Tradução dos autores).

Para Dionísio, a hierarquia consistia então em um evento fundador, o qual possibilitava a integração de um conjunto diversificado de elementos - expressão da relação unitiva entre as pessoas humanas e as três Pessoas divinas -, sem que, com isso, fosse instituída uma unicidade, diluidora das diferenças.

\footnotetext{
${ }^{7}$ Destacam-se os dois volumes publicados por G. Théry em 1932 e 1937, seguidos pelo livro de M. R. Roques sobre a especificidade do pensamento cristão de Dionísio, em 1954.
} 
Se Dionísio adota uma linha neoplatônica, completamente distinta da perspective certeauniana, nem por isso os dois deixam de esclarecer-se mutuamente; Certeau aproxima-se do pensamento do Pseudo-Areopagita, ao destacar a transposição incessante de sentido, a qual promoveria uma desestabilização renovadora (BUARQUE, 2004). Assim, para o jesuíta francês, ser tomado, misticamente, pelo desejo do outro conduz a uma permanente autodesinstalação, mas isso, paradoxalmente, dá lugar a um novo e vital elã, sem nome e sem rosto, recriado pelo "amor muito elevado" (1982a, p. 409):

O corpo testemunha aqui, com efeito, o desejo de se desfazer de uma possessão. Ele trabalha em um 'abandono', caso se prefira. Ele procura desembaraçar-se de presilhas que o aprisionam em códigos, visões de mundo e de si, maneiras de viver e de pensar. Não é casual que a mística seja associada à histeria. Há aqui a vontade de subtrair-se ao que fala do lugar do sujeito, que o determina, que apaga toda expressão do desejo singular. O corpo manifesta a evasão que faz com que a mística não possa ser experimentada a não ser como uma ameaça à instituição (CAUSSE, 2014. Tradução dos autores).

Em seus estudos sobre a mística, Michel de Certeau atentou para a expressão desse desejo e desse encontro através de linguagens corporais (como gemidos, sussurros e até gritos), introduzindo um discurso de códigos marginais. Se tais "ruídos" eram comumente tidos como um "excesso" ou "transbordamento", o que eles desvelavam, de acordo com De Certeau, era a carência de uma estrutura de significação insuficientemente ampla para contê-lo: "É mais da ordem do excesso e da abertura. É um puro esvair-se. Ela é desrazão, porque não é rentabilizável. Partida e ultrapassagem, gesto poético de abrir o espaço, de ir além da fronteira, de jogar pela janela, de arriscar mais” (DE CERTEAU, 1987, p. 262. Tradução dos autores). E é justamente esta ausência (ou excesso) que, sem negar ou romper com o imaginário existente, inclusive na relação do sujeito com a corporeidade, permite a constituição de "brechas" em seu interior, de onde emergem o novo e as diferenças. 
Mas, atenção, alerta De Certeau: o êxtase, na mística, como uma modalidade peculiar de transpasse do Outro em si, não é algo prioritário, que precisa ser atingido:

[...] poder-se-ia dizer que é como a barreira do som: quando se passa de um espaço a outro, da organização de um mundo de objetos à questão do sujeito, então se ultrapassam fronteiras fixadas, como se avança além da barreira do som, quando se altera a velocidade. O êxtase ou os fenômenos psíquicos ou físicos marcam esta fronteira. Mas todos os místicos dizem repetidamente que, deter-se nesses episódios de mudança de espaço, para me ater à minha comparação, é equivocar-se completamente sobre o que consiste a mística. Pelo contrário, a mística avança sempre mais longe e tende para o que um dos grandes místicos do final da Idade Média, Ruusbroec, chamava de 'a vida comum', ordinária [...], mas vivida e pensada de forma diferenciada (DE CERTEAU, s.d., p. 104-116. Tradução dos autores).

Em todos esses casos, a mística apresenta-se inquestionavelmente mediatizada pelo corpo: em sua vivência, o corpo fala, simultaneamente, do que ele carece e o faz sofrer, daquilo que o transpassa e excede, do impossível deslocamento, ao menos com tal intensidade, através da palavra enquanto representação e saber sistematizado.

Logo, se os espirituais renanos dos séculos XIII e XIV, ou ainda são João da Cruz, ainda defendiam uma mística sem mediações (mesmo físicas), já com Teresa d’Ávila e depois dela, a mística assume explicitamente expressões físicas,

[...] relativas a uma capacidade simbólica do corpo, mais do que a uma encarnação do Verbo. Ela acaricia, ela fere, ela eleva a gama de percepções, ela anseia em extremo por aquilo que lhe excede. Ela 'fala' cada vez menos. Ela é traçada em mensagens ilegíveis sobre um corpo transformado em emblema ou em memorial gravado pelas dores de amor (DE CERTEAU, 1982a, p. 14. Tradução dos autores).

Enfim, a mística, para De Certeau, assinala uma erótica, quer dizer "um jogo do escondido e do desvelado, da presença e da ausência. Existe o gozo, mas referido ao mistério do outro, o que continuamente escapa ao eu e que perdura, impossível de possuir" (CAUSSE, 2014. Tradução dos autores). 
Não casualmente, na Europa moderna, quando a mística declina, uma erótica aparece. Isso não é simples coincidência. Ambos referem-se à "nostalgia" provocada pelo retraimento progressivo de Deus como único objeto de amor. A perda desse único, malgrado todas as descobertas e conquistas, instaura a ausência e o “fantasma”, tão citado pela psicanálise. Tantas possessões (de terras, de riquezas, de mulheres) retratam o desespero dessa perda. Desde o século XIII, uma lenta desmistificação religiosa é acompanhada por uma mistificação amorosa. Deus é substituído pelo “outro”, pela mulher (pois a literatura então era masculina). A palavra divina (com valor e natureza físicas) é substituída pelo corpo amado (que não é menos espiritual e simbólico). Mas esse corpo também escapa e a escrita sobre ele é um outro lamento de sua perda (DE CERTEAU, 1982a, p. 12-13).

Paulatinamente, porém, outros “corpos místicos” foram sendo produzidos pelo cristianismo em uma sociedade que não se apresenta mais como hegemonicamente religiosa. Um deles, conforme indica De Certeau, veio a ser produzido pelos movimentos carismáticos e pentecostais, mesclando a glossolalia com a dispersão de um sentido integrador - o falar em línguas implica o esvaziamento dos conteúdos e referentes, junto à individualização e à subjetivação do crer.

À sua maneira, os grupos carismáticos que se multiplicaram nesses últimos anos exemplificam o mesmo tipo de trânsito, em alinhamento às formas contemporâneas da 'sociedade do espetáculo'. Uma necessidade de crer, exacerbada pelo vazio dessa sociedade, conjuga-se à necessidade de um pertencimento cujo conteúdo é, ele também, tornado um vazio. [...] Esta espiritualidade do 'homem ordinário' se junta a uma consciência comum de não mais poder transformar a ordem das coisas, mas ela lhe confere um valor inominável, o Espírito, e o poder miraculoso de se encontrar no quase nada - uma cotidianidade privada de legitimação, palavras privadas de sentido (DE CERTEAU, 1987, p. 312. Tradução dos autores). ${ }^{8}$

Já o segundo corpo, ao invés de dispersar o sentido, promove sua transposição e concentração em um lócus sociopolítico. Assim, ele remete às

\footnotetext{
${ }^{8}$ Ver também GEFFRÉ, 1991, p. 164.
} 
militâncias sociopastorais do cristianismo, as quais procuram nas pequenas comunidades ou sob a forma de engajamentos populares, uma maneira específica de viver a fé. Desta feita, o "corpo" místico-religioso foi, sobretudo entre as décadas de 1960-1980, reencontrado no mundo do trabalho e corporificado nos "pobres", expressão de uma expropriação econômico-social (e também cultural). Mais uma vez, parte-se de uma perda, de um vazio anterior que, contudo, adquire conotações completamente distintas:

Trata-se, assim, para os cristãos, de colaborar com causas que não são as suas, uma vez que eles não possuem mais um ‘solo' próprio. Dessa forma, uma mutação qualitativa inscreve-se nessa passagem de um fazer-acaridade para um fazer a justiça. [...] Em seu trânsito para fora do corpo eclesial desfeito para a cidade política secular, muitos militantes inspiraram-se na 'teologia da libertação', na ótica de Gustavo Gutierrez, Joseph Comblin etc., quer dizer, de uma prática teológica inserida em outras práticas, indissociáveis de solidariedades táticas, submissas às movências e às urgências de uma luta histórica (DE CERTEAU, 1987, p. 309. Tradução dos autores).

\section{Em outra passagem, De Certeau reitera:}

Mais amplamente, o Estado, ou a cultura, ou a classe, passaram a exercer o papel que as Igrejas se conferiam a si mesmas como mediações sociais de sentido. [...] A vida do povo é a mediação social do sentido. Seu trabalho e suas ambições compõem a linguagem democrática em função da qual se elaboram os discursos relativos à vida, à morte, às questões essenciais da existência. Estes discursos são múltiplos, e não redutíveis a um único; construídos, e não recebidos ou fixados por uma ortodoxia [...] Certos teólogos cristãos têm levado a sério esses novos 'lugares teológicos' (DE CERTEAU, 1987, p. 258-259. Tradução dos autores).

\section{Conclusão}

O corpo como ficção (ou representação), instituição (ou normatização) e mística (êxodo ou êxtase em busca do outro/Outro), tal como estudado por Michel de Certeau, é sem dúvida uma contribuição importante para os estudos das ciências humanas em geral, e das ciências da religião e da teologia em particular. 9 Não por

\footnotetext{
${ }^{9}$ Ver a este propósito, sobretudo para a compreensão do corpo como representação (fiçção), o estudo: DE MORI, Geraldo; BUARQUE, Virgínia. Corporeidade-Encarnação: teologia em diálogo. In Perspectiva Teológica, V. 46, 129, p. 187-214.
} 
acaso, vários projetos de estudo sobre o corpo, desenvolvidos nas últimas décadas, mostram como a leitura certeauniana é fecunda para captar as variações da compreensão do corpo na época moderna e contemporânea. ${ }^{10}$

No campo específico da teologia (e das ciências da religião), este tipo de leitura pode contribuir para que as vozes fragilizadas do tempo presente (como as de sujeitos desqualificados por perspectivas étnicas, de gênero, de nacionalidade, etc., ou a dos sujeitos vulneráveis produzidos pela época pós-moderna) desdobrem os sentidos do corpo provenientes da experiência mística descrita por De Certeau. De fato, enquanto a erótica deslanchada pela cultura ocidental acabou por apresentar o corpo como um objeto de vendagem, dissociando-o de um transpasse pelo sagrado e pelo afeto, distintos grupos socioculturais foram submetidos a variadas (e mutuamente reforçadas) práticas de subalternização, acompanhadas por uma sistemática espoliação das referências identitárias que não estivessem em conformidade com os papeis sociais que lhe eram estipulados. Muitos grupos, sobretudo na América Latina, e no âmbito específico de muitas igrejas cristãs, buscaram resgatar a identidade e a dignidade desses grupos, conferindo nova pertinência à experiência da mística. Michel de Certeau, como os agentes eclesiais que se colocaram a seu serviço, não os via somente como vítimas passivas. Pelo contrário, eles mostraram como esses grupos empregavam criativamente seus parcos recursos, sua linguagem - e seus corpos - de forma a combater ou a evadirse de sistemas de exploração socioeconômica ou do autoritarismo político:

Pode acontecer qualquer coisa. Tudo é possível. De fato, de tempos em tempos, ruídos de corpos, gritos, vozes escondidas, movimentos dissonantes infringem a codificação social. Alguma coisa do corpo fala que não há linguagem alguma na civilização e que não há mais referências em um simbólico. Sobre isso, nada afiança. Súbitas violências, irrupções romanescas, 'experiências' de possuídos ou de místicos abrem exibições de corpos no tecido do código (DE CERTEAU, 2002, p. 411).

\footnotetext{
${ }^{10}$ A obra de CORBIN, Alain; COURTINE, Jean-Jacques; VIGARELLO, Georges. História do corpo. Petrópolis: Vozes, 2000, é, do ponto de vista da historiografia, emblemática, retomando a evolução nas representações do corpo desde o final do período renascentista até a época contemporânea.
} 
Face à expropriação, Michel de Certeau defendia uma dupla postura. Por um lado, ele afirmava ser crucial conferir-se reconhecimento (ou seja, dignidade e cidadania) a esta alteridade, que poderia comportar o "vizinho irreconhecível ou o irmão separado, posto de lado na rua, encerrado nas prisões, acantonado junto aos miseráveis, ou ignorado, quase mítico, em uma região para além das fronteiras” (DE CERTEAU, 1991, p. 13-14. Tradução dos autores). Em paralelo, ele também destacava que, por vezes, certos sujeitos e grupos adotavam uma singular postura político-existencial, por ele aproximada da experiência mística: a de permanecer esvaziado de garantias, verdades, conquistas, empoderamentos, caso essas dimensões não lhes trouxessem uma aproximação com o outro, tão almejada. Tais "místicos", de ontem e de hoje, aspiravam por uma relação, mais do que por uma autoafirmação ou uma revanche. Longe de evocar uma virtude "inata" ou "natural", De Certeau salientava que o contexto de desqualificação lançou tais indivíduos em uma disposição alternativa ao exercício do poder e à relação com a alteridade:

\begin{abstract}
Dessa maneira, os místicos não se distanciam das ruínas que os envolvem. Eles aí permanecem. Eles dirigem-se a elas. Gesto simbólico, Inácio de Loyola, Teresa d'Ávila, vários outros, desejaram entrar em uma Ordem 'corrompida'. Não que eles simpatizassem com a decadência. Mas esses lugares desfeitos, quase deserdados - lugares de abjeção, de prova (como antigamente os 'desertos' para onde os monges dirigiam-se a fim de combater os espíritos malignos) e não lugares certificadores de uma identidade e de uma salvação - representam a situação efetiva do cristianismo contemporâneo. Eles são os teatros das lutas presentes (DE CERTEAU, 1982a, p. 42-43. Tradução dos autores).
\end{abstract}

Tais sujeitos e grupos, portanto, não escamoteavam sua fragilidade, pois consideravam que com isso mantinham certa abertura, existencial e política, ao deixar-se surpreender por esse “outro"/Outro que chega, ansiosos por encetar uma interlocução com ele, na qual o corpo apresenta-se como dimensão fundamental:

A voz, feita de sopro, seria um fragmento privilegiado que garante um corpo e que anuncia sentido. [...] Como ela o foi na religião, não é surpreendente que permaneça, na experiência cotidiana, alternadamente erótica e dolorosa, o terceiro elemento que contradiz o positivismo e o idealismo e que constitui o abrigo de nossas frágeis apreensões do corpo, isto é, do outro (DE CERTEAU, 2002, p. 412). 


\section{REFERÊNCIAS}

BACZKO, Bronislaw. A imaginação social In: LEACH, Edmund et alii. Enciclopédia Einaudi: Anthropos-Homem. Lisboa: Imprensa Nacional/Casa da Moeda, 1985.

BERTRAND, Dominique. La théologie négative de Michel de Certeau. In: CENTRE THOMAS-MORE (org). Michel de Certeau ou la Différence Chrétienne. Paris: Du Cerf. 1991.

BROWN, Peter. Corpo e sociedade: o homem, a mulher e a renúnica sexual no início do cristianismo. Rio de Janeiro: Jorge Zahar, 1990.

BUARQUE, Virgínia A epistemologia negativa de Michel de Certeau. Trajetos: Revista do Programa de Pós-Graduação em História da Universidade Federal do Ceará, Fortaleza, v. 5, n. 9/10, p. 231-248, 2004.

CAUSSE, Jean-Daniel. Le corps et l'expérience mystique. Analyse à la limière de Jacques Lacan et de Michel de Certeau. Cahiers d'Études du Religieux. Recherches

Interdisciplinaires, v. 13, jul. 2014. Disponível em: <http://cerri.revues.org/1345>. Acesso em: 24 jun. 2016.

CORBIN, Alain; COURTINE, Jean-Jacques; VIGARELLO, Georges. História do corpo. Petrópolis: Vozes, 2000.

DE CERTEAU, Michel. A Cultura ao Plural. Campinas: Papirus, 1995.

DE CERTEAU, Michel. La faiblesse de croire. Paris: Seuil, 1987.

DE CERTEAU, Michel. História e Psicanálise: entre ciência e ficção. Belo Horizonte: Autêntica, 2011.

DE CERTEAU, Michel. A Invenção do Cotidiano. Petrópolis: Vozes, 1994.

DE CERTEAU, Michel. La Fable Mystique, 1. XVIe.- XVIIe. Siècles. Paris: Gallimard, 1982a.

DE CERTEAU, Michel. A Escrita da História. Rio de Janeiro: Forense Universitária, 1982b.

DE CERTEAU, Michel. Histórias de corpos. Projeto História, São Paulo, v. 25, p. 407312, dez. 2002.

DE CERTEAU, Michel. L'Étranger ou l'Union dans la Différence. Paris: Desclée de Brouwer, 1991.

DE MORI, Geraldo; BUARQUE, Virgínia. Corporeidade-Encarnação: teologia em diálogo. Perspectiva Teológica, Belo Horizonte, v. 46, n. 129, p. 187-214, 2014. 
FLORES, Maria Bernardete Ramos; NORA, Sigrid. Corpo, arte e história. Do Corpo: Ciências e Artes, Caxias do Sul, v. 1, n. 2, p. 1-14, jul./dez. 2011.

GEFFRÉ, Claude. Le non-lieu de la théologie chez Michel de Certeau. In: CENTRE THOMAS-MORE (org). Michel de Certeau ou la Différence Chrétienne. Paris: Du Cerf. 1991.

GESCHÉ, Adolphe; SCOLAS, Paul. O Corpo, Caminho de Deus. São Paulo: Loyola, 2009.

GIARD, Luce. Mystique et politique, ou l'institution comme objet second. In: GIARD, Luce; MARTIN, Hervé; REVEL, Jacques. Histoire, Mystique et Politique. Michel de Certeau. Grenoble: Jérôme Millon, 1991.

JOSGRILBERG, Fábio B. Cotidiano e Invenção: os espaços de Michel de Certeau. São Paulo: Escrituras, 2005.

KANTOROWICZ, Ernst H. Os Dois Corpos do Rei. São Paulo: Cia. das Letras, 1998.

LUBAC, Henri de. Corpus Mysticum: l'eucharistie et l'Église au Moyen Âge: étude hisotirque. Paris: CERF, 2009 (Oeuvres Complètes, v. 15).

MARTÍNEZ, Ignacio Gárate. Entretien avec Michel de Certeau. Figures de la Psychanalyse, v. 8, p. 104-116. Disponível em: <http://www.lettre-de-lamagdelaine.net/IMG/pdf/Garate_De_Certeau.pdf>. Acesso em: 16 ago. 2016. Tradução da autora.

NOGUEIRA, Maria Luísa Magalhães. Corpos políticos. In: Anais do III Seminário Internacional Urbicentros. Salvador, 22 a 24 out. 2012. Disponível em: < http://www.ppgau.ufba.br/urbicentros/2012/ST216.pdf>. Acesso em 16 ago. 2016.

PINTO, Aline Montenegro. Um historiador e suas travessias. Topoi, Rio de Janeiro, v. 13, n. 24, p. 196-201, jan.-jun. 2012.

QUADROS, Eduardo Gusmão. A viviência religiosa como objeto da história das religiões: uma leitura de Michel de Certeau. Impulso, Piraciba, v. 37, n. 15, 101-109, 2004.

RANKE-HEINEMANN, Uta. Eunucos pelo Reino de Deus. Mulheres, sexualidade e a Igreja Católica. $3^{\mathrm{a}}$. ed. Rio de Janeiro: Reccord/Rosa dos Tempos, 1996.

RIZZI, Philippo. De Certeau, um "sujeito de inquietação verdadeira”. IHU On-Line, 12 jan. 2016. Disponível em: <http://ihu.unisinos.br/noticias/550739-de-certeau-umqsujeito-de-inquietacao-verdadeiraq>. Acesso: 12 jun. 2016.

ROSIER-CATACH, Irène. Éléments de pragmatique dans la grammaire, la logique et la théologie médiévales. Histoire, Épistémologie, Langage, Lille, v. 20, n. 1, p. 117-132, 1998. 
SOUSA, Emilene Leite de. In(corpo)ração. Ou de como a sociedade se inscreve nos corpos dos indivíduos. Anais do XXVII Congreso de la Asociación Latinoamericana de Sociología. VIII Jornadas de Sociología de la Universidad de Buenos Aires. Asociación Latinoamericana de Sociología, Buenos Aires, 2009.

VIDAL, Daniel. Figures de la mystique: le dit de Michel de Certeau. Archives de Sciences Sociales des Religions, Paris, v. 2, n. 58, p. 187-194, 1984. 